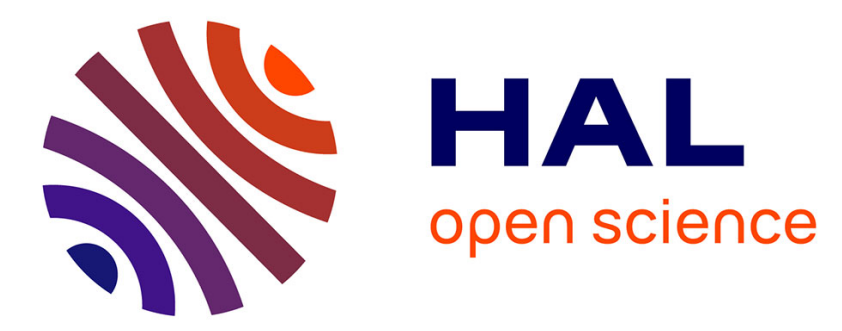

\title{
Probability modelling of shear strength parameters of RCC gravity dams for reliability analysis of structural safety
}

Claudio Carvajal, Laurent Peyras, Claude Bacconnet, Jean-Pierre Bécue

\section{To cite this version:}

Claudio Carvajal, Laurent Peyras, Claude Bacconnet, Jean-Pierre Bécue. Probability modelling of shear strength parameters of RCC gravity dams for reliability analysis of structural safety. European Journal of Environmental and Civil Engineering, 2011, 13 (1), pp.91-119. 10.1080/19648189.2009.9693087 . hal-02454707

\section{HAL Id: hal-02454707 \\ https://hal.science/hal-02454707}

Submitted on 24 Jan 2020

HAL is a multi-disciplinary open access archive for the deposit and dissemination of scientific research documents, whether they are published or not. The documents may come from teaching and research institutions in France or abroad, or from public or private research centers.
L'archive ouverte pluridisciplinaire HAL, est destinée au dépôt et à la diffusion de documents scientifiques de niveau recherche, publiés ou non, émanant des établissements d'enseignement et de recherche français ou étrangers, des laboratoires publics ou privés. 
To cite this article: Claudio Carvajal, Laurent Peyras, Claude Bacconnet \& Jean-Pierre Bécue (2009): Probability modelling of shear strength parameters of RCC gravity dams for reliability analysis of structural safety, European Journal of Environmental and Civil Engineering, 13:1, 91-119.

To link to this article: $\underline{\text { http://dx.doi.org/10.1080/19648189.2009.9693087 }}$

\title{
Probability modelling of shear strength parameters of RCC gravity dams for reliability analysis of structural safety
}

\author{
Text published in: \\ European Journal of Environmental and Civil Engineering \\ (2009) Vol.13, No.1, pp.91-119
}

\section{Claudio Carvajal* ${ }^{*}$ Laurent Peyras** ${ }^{*}$ Claude Bacconnet*** Jean- Pierre Bécue*}

* SAFEGE Ingénieurs Conseils

Parc de l'Ile 15/27 rue du Port 92022 Nanterre Cedex. France

\{claudioandres.carvajalmoncada, jean-pierre.becue\}@safege.fr

** Cemagref

3275 route de Cézanne - CS 40061 - 13182 Aix en Provence. France

laurent.peyras@cemagref.fr

*** LaMI, Polytech' Clermont Ferrand, Université Blaise Pascal 24, avenue des Landais - BP 206 - 63174 Aubière Cedex. France

claude.bacconnet@univ-bpclermont.fr 


\begin{abstract}
Modelling concrete shear strength is the main difficulty in probabilistic reliability analysis of gravity dam structural safety. The main reason arises from the lack of test data on the parameters. This paper proposes a procedure for probability modelling of Roller Compacted Concrete (RCC) gravity dam shear strength based on all tests performed during dam construction and all available data. The procedure embraces several methods: statistical analysis of RCC density, analysis of scatter at different spatial scales, data unification, and a physical formulation of the RCC intrinsic curve. A case study demonstrates the applicability of the procedure on an existing RCC gravity dam. The probability distributions obtained are incorporated into the formulation of the shear strength limit state using a first order reliability method and Monte Carlo simulations.
\end{abstract}

KEY WORDS: gravity dam, RCC, strength, probability, reliability.

\title{
Résumé
}

La modélisation des résistances au cisaillement du béton constitue la principale difficulté à une analyse fiabiliste de la sécurité structurale des barrages poids. Cet article propose une démarche pour la modélisation probabiliste des résistances au cisaillement des barrages BCR mobilisant les essais réalisés lors du chantier et les informations disponibles. La démarche fait intervenir différentes méthodes: l'analyse statistique des densités du BCR, l'analyse des dispersions aux différentes échelles spatiales, l'unification des données, une formulation physique de la courbe intrinsèque $d u B C R$. Une étude de cas montre l'applicabilité de la démarche sur un barrage poids en BCR existant. Les lois de probabilité obtenues sont intégrées dans la formulation de l'état limite de résistance à l'effort tranchant par une analyse fiabiliste de premier ordre et des simulations de Monte Carlo.

MOTS-CLÉS: barrage, barrage poids, BCR, modèle, probabilité, résistance, fiabilité.

\section{Introduction}

In the civil engineering profession, dams have always been considered as special structures not falling within the ambit of regulations applicable to bridges, tunnels and the building industry in general. Eurocodes, which are destined eventually to harmonise the European construction market, are not intended to be used directly for special structures such as dams. Dams have always been assessed through a deterministic approach based on allowable stress (Peyras et al., 2006). This is a fact found generally in the leading French and international standards (FRCOLD 2002), (USBR 1987) and (USACE 1995).

The situation has recently undergone a change with FRCOLD's publication of French guidelines for analysing gravity dams using a semi-probabilistic limit state procedure (FRCOLD 2006). In these guidelines, safety is handled through partial coefficients directly incorporating the uncertainty attaching to the various parameters for strength, loads and limit states considered in the safety assessments (Peyras et al., 2008).

This paper refers to an $R \& D$ programme to develop probabilistic reliability methods for assessing the structural safety of gravity dams (Carvajal et al., 2007). This was a joint effort 
allying SAFEGE consulting engineers, Cemagref - a French dam monitoring and inspection government agency - and the Engineering Mechanics Laboratory (LaMI) at Blaise Pascal University in Clermont-Ferrand, France.

Various other international investigations have been carried out on concrete gravity dams: (USACE 1998, 2000) use early reliability methods (FOSM) to study resistance to sliding, (Ellingwood et al., 2001) and (USACE 1998) assess structural safety from fragility curves, (McDonald et al., 1999) uses Monte Carlo simulations for the analysis of static stability, etc.

Reliability methods handle strength variability and load randomness through a probability approach. The advantages of this depend on the relevance of the probability distributions used to represent strengths and loads. The works identified use conventional reliability methods for assessing dam safety; to model strengths, they make use of declarative probability distributions based on expert advice. This is the background to our work reported here, which is to offer methodologies for modelling random variables, especially for modelling strength parameters.

Turning to loads, the main load acting on dams is water load. It s relatively easy to account for in probability terms because we have the hydrological probability distributions used for flood modelling (FRCOLD 1994). The design flood which sets the maximum load on the dam, is assessed, at a given return period, from statistical distributions of rainfall and flood streamflows. By making use of the hydrological distributions used in engineering, we propose methodologies for modelling the water load acting on the dam (Carvajal et al., 2008).

Turning to strengths, the main parameters governing the gravity dam stability are the concrete unit weight fixing the self-weight of the dam, the compressive and tensile strength and the shear strength represented by cohesion and tangent of the internal friction angle of the material. These last two parameters are involved in the shear strength limit state condition, which represents the main gravity dam failure mechanism. Moreover, shear strength limit state is closely linked to cracking mechanism; so the hydro-mechanical aspect has to be considered: the initiation of crack on the upstream face of a dam might be capable of introducing the full uplift in the crack which further penetrates the dam body (FRCOLD 2006).

Probability modelling of gravity dam strength is a complex task. For the last 20 years or so, modern gravity dams have been built on the Roller-Compacted Concrete - RCC - model (BaCaRa 1996) in which a lean concrete mix is spread and compacted with earthmoving machinery. Probability modelling of Shear Strength Parameters of RCC reveals major problems: (1) only very few shear strength tests are preformed on the RCC material, (2) the tests that are available are control tests not directly aimed at yielding data on strength as required in limit state work, and (3) the spatial scale of the analysis of variability of the strength parameters must be substantially commensurate with the area of determination of the limit state shear strength of a layer of roller compacted concrete or RCC construction joint governing the design of the dam. These problems involving the available data explain why the research work that has been done on the subject use probability distributions set at the outset by the experts, basing their thoughts on a few strength determinations.

In view of these problems, our research focused on proposing methods for the probabilistic modelling of strength parameters, using all available data, in particular, the results of the control tests performed during construction. This paper describes various methods for writing probability models of RCC shear strength and how they are used in a reliability analysis of structural safety. Several approaches are possible: (1) analysis of scatter in the strength parameters at different spatial scales, (2) statistical analysis of RCC compaction and compressive strength, (3) data unification for tensile strength variability, and (4) use of a 
physical formulation of the concrete shear strength criterion for investigating shear strength variability.

The first part of the paper introduces RCC gravity dam construction technology and analyses available data for characterising strength parameters. The second part proposes methods for the probabilistic modelling of strengths on the basis of the available data. The process is illustrated in the third part of the paper by describing the case of an RCC gravity dam: modelled strengths are incorporated into the formulation of the shear strength limit state by a First Order Reliability Method and Monte Carlo simulations.

\section{RCC gravity dam technology and available data}

\subsection{RCC gravity dams}

Roller Compacted Concrete RCC is a material made up of aggregate, water and cementitious material placed in the works like earthfill and compacted by roller (BaCaRa 1996). RCC cement and water ratios are generally lower than for a conventional vibrated concrete. RCC dams usually have a cement content of around 100 to $150 \mathrm{~kg}^{\mathrm{ker} \mathrm{m}^{3}}$. Admixtures such as fly ash, blast furnace slag or pozzolans slow down the setting time and reduce the heat of hydration of the RCC mix. RCC therefore has an inherent variability in its strength properties associated with the natural variations in aggregate, and its sensitivity to cement and mix water content. Variations also arise, depending on mixer efficiency.

Construction plant for an RCC gravity dam normally consists of a bulldozer for spreading the material, a heavy roller for compacting the major part of the layer to the required density, and a light roller for compacting the edges of the layer. Water is sprayed on the compacted layer as curing agent before placing the next layer. This construction method has been found to produce a dense concrete, yet one that has a potential for variation of the strength properties linked with high placement rates and segregation potential, as well as environmental factors such as the weather.

Each layer of dam material is completed in the same unit time (one to a few unit layers completed in the same day) using material from several batches. This leaves room for potentially large variations in the strength parameters from one layer to another in the dam.

Taken together, all these items contribute to producing a material with intrinsically more variability in its properties than a conventional vibrated concrete (McLean et al., 1988).

\subsection{Limit states}

RCC dams are built in thin layers measuring about $30 \mathrm{~cm}$ each. This construction method has consequences on the anisotropic mechanical behavior of RCC: (1) at the dam scale, this leaves an abundance of construction joints that are planes of weakness as regards permeability and shear strength; (2) at the local scale, symptoms of anisotropy were also noted on the tensile strength due to a horizontal alignment of the aggregates and the direction of application of the energy of compaction (BaCaRa 1996). Therefore, these construction joints are the places for the strength parameters to be inserted into the limit state computation (FRCOLD 2006). 
Gravity dams are designed for stability under three limit states (FRCOLD 2006): (1) crack opening, (2) insufficient shear strength and (3) insufficient compressive strength (which is only the governing case on very large dams). Failure computations are conducted in the body of the dam, on construction joints, at the dam-foundation contact and within the foundation. In this paper, we are only interested in the first two limit states and only in the body of the RCC dam.

On the subject of crack opening: a dam is exposed to load which might cause tensile stresses to appear on the upstream face. The concrete exhibits only poor tensile strength, especially at the construction joints. The crack opening limit state in RCC estimates the risk of crack initiation and the possibility of crack growth horizontally from its origin on the upstream face. The no-cracking condition is written:

$$
s_{N}^{\prime}(x)>-f_{t}
$$

in which: $s_{N}(x)$ is the is the normal effective stress of abscissa $(x)$ of the section considered $\left(s_{N}{ }_{N}(x)\right.$ is positive for compression stresses), and $f_{t}$ is the RCC tensile strength.

The computation process is to find the length of the fissure such that, at the upstream end of the crack-free part, the normal effective stress $s_{N}(x)$ in the material equals RCC tensile strength. This yields information on the crack-free length $L^{\prime}$ in the horizontal section considered.

Concerning limit state shear strength, we check the generalised shear strength on a horizontal section along an RCC construction joint. The limit state condition expresses a Mohr-Coulomb type resistance criterion:

$$
C \cdot L^{\prime}+(N-U) \cdot \tan (\varphi)>T
$$

in which:

$-C$ and $\varphi$ are the cohesion and internal friction angle parameters of the RCC,

$-L^{\prime}$ is the crack-free length of the construction joint calculated above,

$-N$ and $T$ are the normal and tangential components of the external forces acting on the section concerned,

$-U$ is the resultant of the uplift pressures at the level of the section concerned.

From this brief review of limit states, the following points emerge:

- The RCC properties we need to express in a probabilistic model are shear strength $C$ and $\tan (\varphi)$, tensile strength $f_{t}$ and unit weight $\gamma_{\mathrm{rcc}}$ of the RCC;

- The analysis of variability must be repeated at several spatial scales:

- for the shear limit state, we are concerned with variability at the scale of a concrete layer between construction joints for shear strength parameters $C$ and $\tan (\varphi)$;

- for the crack opening limit state, we want the local variability contained near the upstream face for the tensile strength parameter $f_{t}$;

- the RCC unit weight $\gamma_{\mathrm{rcc}}$ operates on the load side as the self weight of the dam and so we must consider the dam as a whole. 


\subsection{Available data}

Available tests concerning the properties of materials are performed in the course of dam construction while the workmanship is being very closely monitored. The following control tests are done on RCC:

(1) field trials: Are performed before construction begins in earnest to produce the final RCC design mix, water content and required compaction energy needed to meet the contract specifications. Cores are drilled from the field tests for laboratory crushing strength tests. Tensile strength tests are less frequently done, and shear strength tests even less often. Even when tensile and shear strength tests are performed, only a few tests are made (measured in single figures), and always on materials not retrieved directly from the body of the dam;

(2) mixing plant control tests: Are concerned mainly with grain size distributions, mix water content, temperature, workability and compression and tensile strengths from test specimens taken in the course of the mixing process. These tests characterise compressive and tensile strengths for one RCC layer (a few test units per layer);

(3) controls during construction: Based on frequent measurements of density and water content on all RCC layers (Figure 1). Testing rate is habitually of the order of one test per 200 $\mathrm{m}^{3}$ to $300 \mathrm{~m}^{3} \mathrm{RCC}$ in-place. Concretes temperature and setting time are recorded in order to assess the condition of the RCC surface when pouring the next RCC layer over it.

In short, there are abundant density tests for each horizontal layer of RCC (between 6 and 18 tests per RCC layer in the example in Figure 1);

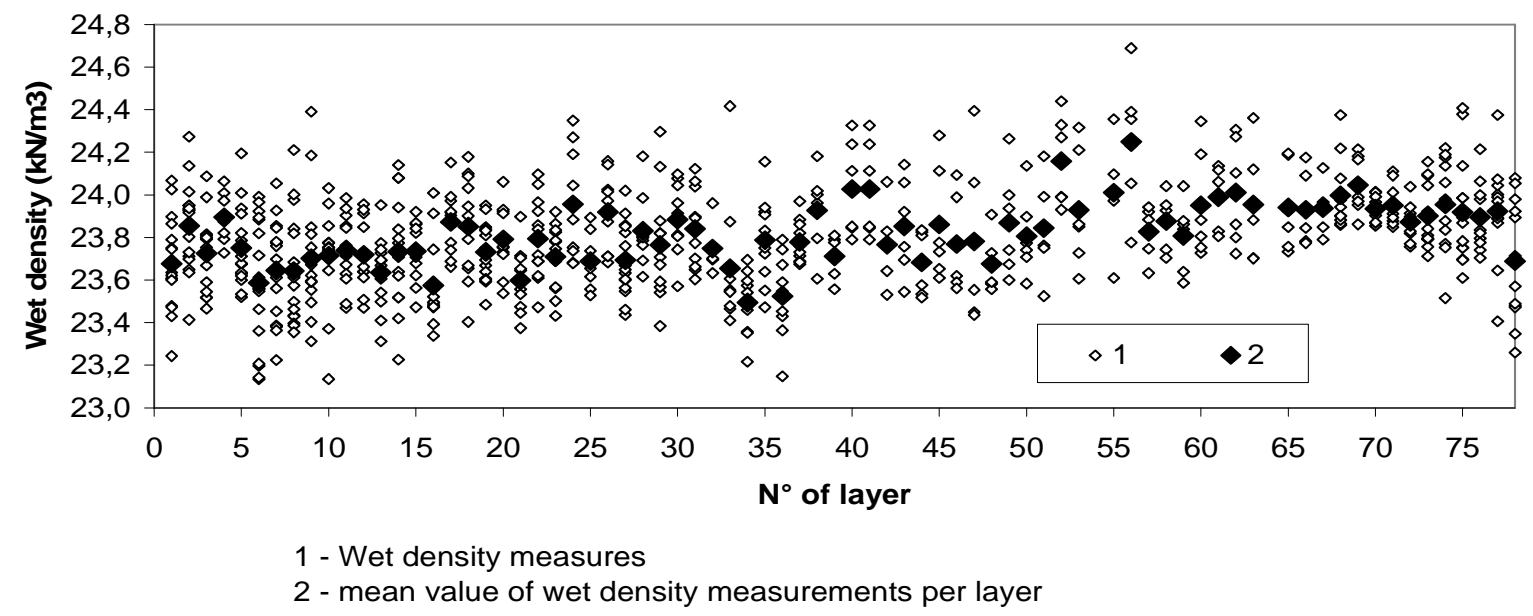

Figure 1. Typical RCC Densities Measured in Compaction Control Tests on an RCC Dam, for Each Layer

(4) post construction controls: Consists of drilling a few vertical cores which may penetrate the whole height of the dam and continue some depth into the foundation. The cores recovered are used to assess densities and compressive and tensile strengths in the different RCC layers and construction joints. There is generally one compressive strength test and one density determination for each horizontal RCC layer (Figure 2). 


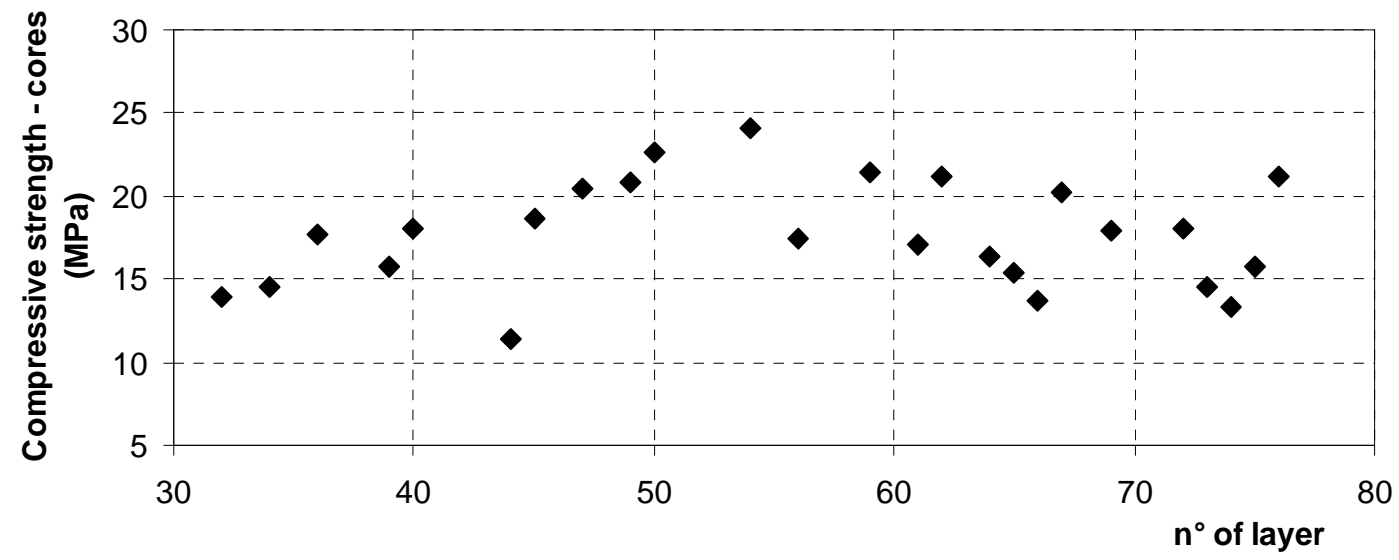

Figure 2. Example of Compressive Strength Values Measured at End of Construction of an RCC Dam on Drill Core

Scrutiny of the data revealed few available measurements for the strength parameters:

- one or two compressive strength measurements per RCC layer;

- little or no tensile or shear strength data.

In fact, no direct statistical analysis can be performed on the tensile and shear strength data and compressive strength cannot be examined at the scale of the RCC layer.

The only RCC property whose variability can be studied at different spatial scales is RCC density measured at the time of the compaction controls.

A tentative approach for modelling strengths would be to look for correlations between compressive strength and density data. If a statistical relationship could be found between these two, it would be possible to determine compressive strength variability through a statistical analysis of density variability at different spatial scales. However, correlation between density and strength parameters is weak, with density variability accounting for only part of the strength variability. We must therefore find another method of probability analysis to reach local scale and layer scale strengths.

\section{Probability modelling of strength parameters}

\subsection{Scale of analysis and general approach}

The analysis of the variability of RCC properties and estimating associated uncertainties must be in agreement with the extent of the zone concerned by the limit states under consideration:

- crack opening concerns the upstream part of an RCC layer (zone 1 in Figure 3). Cracking conditions are in addition potentially very different from one layer to another. Consequently, the probability distribution for tensile strength is looked for at local scale in a local zone contained near the upstream face of the dam;

- deficient shear strength transfers load to the mean shear strength of a construction joint. Determining the shear strength of an RCC dam therefore becomes a question of finding the shear strength of the weakest or worst construction joint. We must therefore look for the 
shear strength probability distribution at the scale of the RCC layer or construction joint (zone 2 in Figure 3);

- the unit weight is involved in the there limit state conditions in computing the dead weight of the dam. We must look for the probability distribution for this parameter at the scale of the dam considered as a whole (zone 3 in Figure 3).

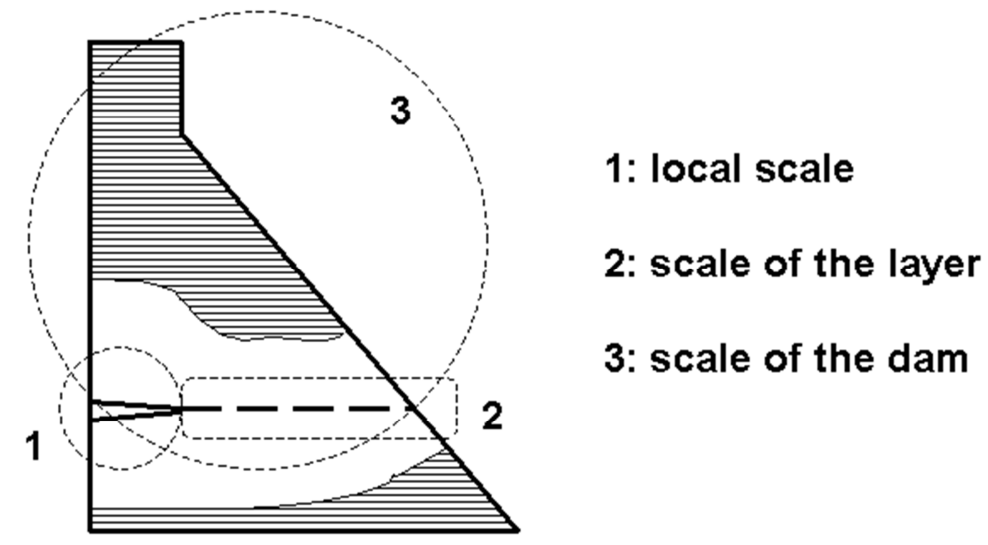

Figure 3. Different Variability Scales

We want to estimate the variability of the RCC properties at the three scales defined above. The general procedure adopted to model the RCC shear strength probability distributions is in four steps (Figure 4):

- step 1: statistical analysis of densities measured in the compaction control tests. We analyse the variability of the density measurements in the RCC compaction control tests, which are plentiful. This allows us to assess scatter in the data at various (local, RCC layer and whole dam) spatial scales;

- step 2: modelling compressive strength through analysis of density data scatter. We perform a statistical analysis of the local compressive strength data from tests on cores and specimens from the mixing plant. Since there are not enough compressive strength test data for each RCC layer, we use the ratios between local scale and layer scale compaction density test scatter. We can then construct a probabilistic modelling of compressive strength at RCC layer scale;

- step 3: modelling tensile strengths by unification method. Using a data unification technique, we construct a model of tensile strength at layer scale and local scale.

- Step 4: modelling of shear strength parameters as a physical relationship. Using a physical formulation of the RCC intrinsic curve, we can estimate the layer-scale shear strength parameters. 


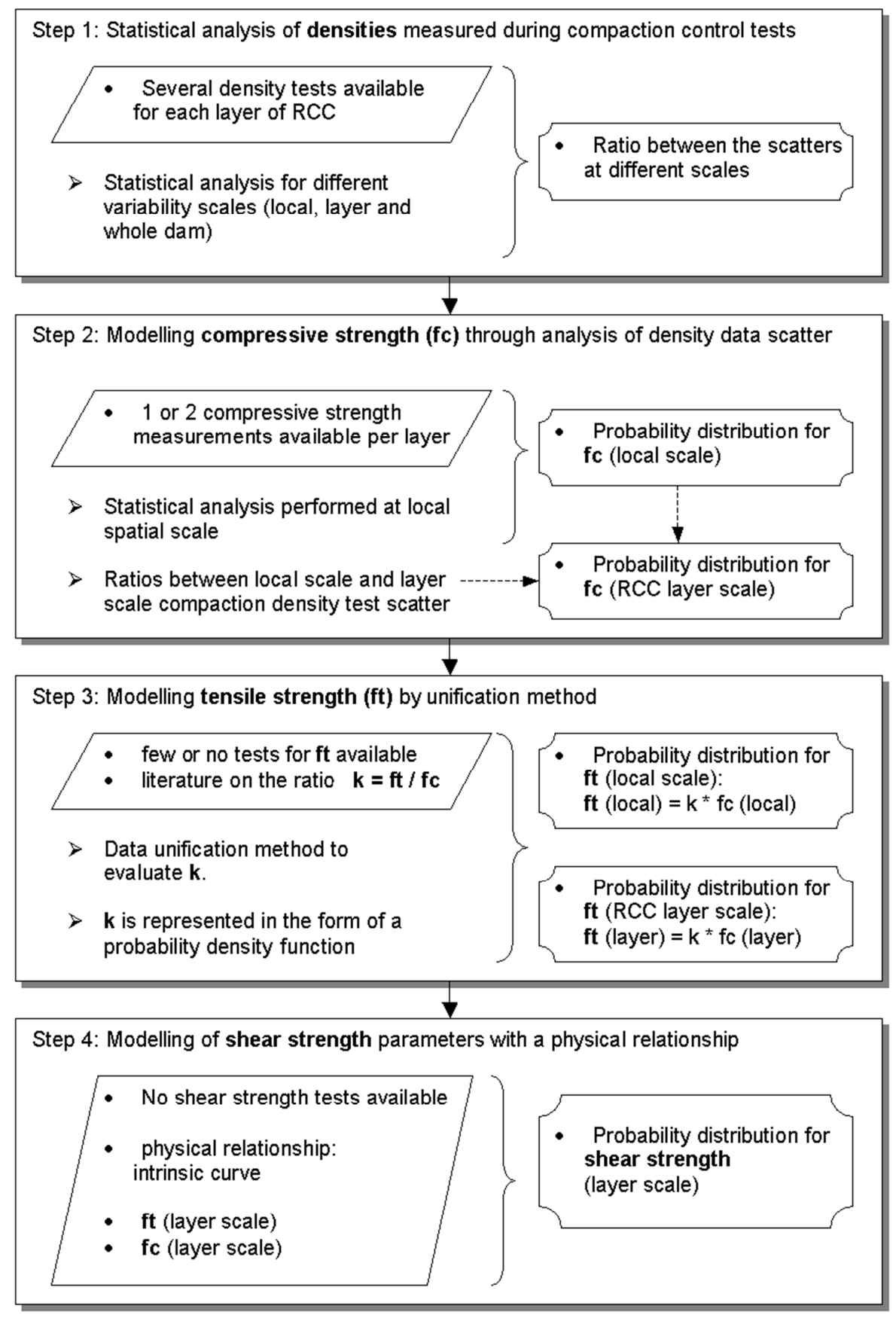

Figure 4. General Procedure Proposed for Modelling Shear Strengths

\subsection{Statistical analysis of density data from compaction control tests}

Making a probability model of a property on the basis of a statistical analysis involves the following routine steps (Favre 2004): (1) construct histograms and empirical distribution functions; (2) identify aberrant values and if applicable correct the data; (3) determine central trend, scatter and histogram shape values; (4) make order of magnitude comparison based on expert judgement and available literature; (5) fit a probability distribution with conformity tests and confidence intervals. 
Probability modelling of RCC density from statistical analysis is applicable because we have a large population of tests performed during the construction stage. This makes it possible to suggest probability distributions for the different scales (local, each RCC layer, whole dam).

Consider the case of an RCC dam for which we have a population of density measurements $\gamma_{\text {rcc }}$ collected in the construction stage. We use the following notation for density $\gamma_{\text {rcc }}$ measured in compaction control tests:

$-J$ is the number of density control tests for each RCC layer;

$-N$ is the number of RCC layers considered at the scale of the dam (Figure 3);

$-z$ is layer number or elevation;

$-\left(\gamma_{\mathrm{rcc}}\right)_{\mathrm{z}}^{\mathrm{j}}$ is the local density measured at a point between 1 and $\mathrm{j}$ on layer $\mathrm{z}$;

$-\mu\left(\gamma_{\mathrm{rcc}}\right)_{\mathrm{z}}$ is the mean of density measurements on layer $\mathrm{z}$;

$-\sigma^{\text {Local }}\left(\gamma_{\mathrm{rcc}}\right)_{\mathrm{z}}$ is the standard deviation of density measurements on layer $\mathrm{z}$;

$-\sigma^{\text {Layer }}\left(\gamma_{\mathrm{rcc}}\right)_{\mathrm{z}}$ is the standard deviation of the normal distribution representing uncertainty on the mean density value on layer z (equation [3]);

$-\mu\left[\mu\left(\gamma_{\mathrm{rcc}}\right)_{\mathrm{z}}\right]$ is the mean of mean layer densities;

$-\sigma\left[\mu\left(\gamma_{\mathrm{rcc}}\right)_{\mathrm{z}}\right]$ is the standard deviation of mean layer densities;

$-\sigma^{D a m}\left(\gamma_{\text {rcc }}\right)$ is the standard deviation of the normal distribution representing uncertainty on the mean of mean density values (equation [4]).

We can suggest a probability distribution for density $\gamma_{\text {rcc }}$ at different spatial scales:

- at local scale, density is modelled by a probability distribution fitted on all the $J$ measurements performed on a layer z. If this is a normal distribution, its parameters can be obtained from the mean $\mu\left(\gamma_{\mathrm{rcc}}\right)_{\mathrm{z}}$ and standard deviation $\sigma^{\text {Local }}\left(\gamma_{\mathrm{rcc}}\right)_{\mathrm{z}}$;

- at RCC layer scale, we are concerned with the mean value $\mu\left(\gamma_{\mathrm{rcc}}\right)_{\mathrm{z}}$ of the density measurements made on the layer and the uncertainty associated with this mean value. If it is assumed that the uncertainty on the mean density can be modelled by a normal distribution, the mean of the distribution is $\mu\left(\gamma_{\mathrm{rcc}}\right)_{\mathrm{z}}$ and its standard deviation $\sigma^{\text {Layer }}\left(\gamma_{\mathrm{rcc}}\right)_{\mathrm{z}}$ is obtained from the equation [3];

$$
\sigma^{\text {Layer }}\left(\gamma_{r c c}\right)_{z}=\sigma^{\text {Local }}\left(\gamma_{r c c}\right)_{z} / J^{1 / 2}
$$

- at whole dam scale, we are interested in the mean of the mean layer densities and the uncertainty attaching to this mean. If we assume that the uncertainty on mean $\mu\left[\mu\left(\gamma_{\mathrm{rcc}}\right)_{\mathrm{z}}\right]$ can be modelled by a normal distribution, then the mean of the distribution is $\mu\left[\mu\left(\gamma_{\mathrm{rcc}}\right)_{\mathrm{z}}\right]$ and its standard deviation $\sigma^{\text {Dam }}\left(\gamma_{\mathrm{rcc}}\right)$ is obtained from the Equation [4]:

$$
\sigma^{\text {Dam }}\left(\gamma_{r c c}\right)=\sigma\left[\mu\left(\gamma_{r c c}\right)\right] / N^{1 / 2}
$$

\subsection{Compressive strength modelling by analysis of density data scatter}

In most cases, we only have one or two measurements of compressive strength per RCC layer from tests on specimens taken at the mixing plant or from drill cores. The number of measurements available per RCC layer is therefore not sufficient to determine directly a 
probability distribution to represent this parameter at RCC layer scale. The procedure adopted to determine a probability distribution at layer scale is as follows.

Note. - We use the following notation for compressive strength $f c$ :

$-\mu(f c)_{\mathrm{z}}$ is the mean compressive strength on layer $\mathrm{z}$

$-\sigma^{\text {Local }}(f c)$ is the local scale standard deviation of compressive strength corresponding to the standard deviation of all available compressive strength measurements.

$-\sigma^{\text {Layer }}(f c)_{\mathrm{z}}$ is the RCC layer scale standard deviation of compressive strength, for layer $\mathrm{z}$.

(1) from the statistical analysis of compressive strength measurements, we can fit a compressive strength probability distribution whose parameters are the mean and standard deviation of the measurements. This probability modelling of compressive strength is a local scale model because each compressive strength measurement involves only a small volume, no bigger than the test specimen;

(2) a smoothed curve fitting the compressive strength measurements provides a first approximation for obtaining the mean value $\mu(f c)_{\mathrm{z}}$ for the $\mathrm{z}$ RCC layer. For example, we may smooth a number representing measurements made in the same time unit (number of measurements per working day);

(3) in order to estimate the scatter in compressive strength at RCC layer level, we make the assumption that the ratio between the scatter (represented by the standard deviation for example) at different scales is the same for RCC density and compressive strength:

$$
\frac{\sigma^{\text {Local }}\left(\gamma_{r c c}\right)_{z}}{\sigma^{\text {Layer }}\left(\gamma_{r c c}\right)_{z}}=\frac{\sigma^{\text {Local }}(f c)}{\sigma^{\text {Layer }}(f c)_{z}}
$$

This assumption is illustrated in the following figure.
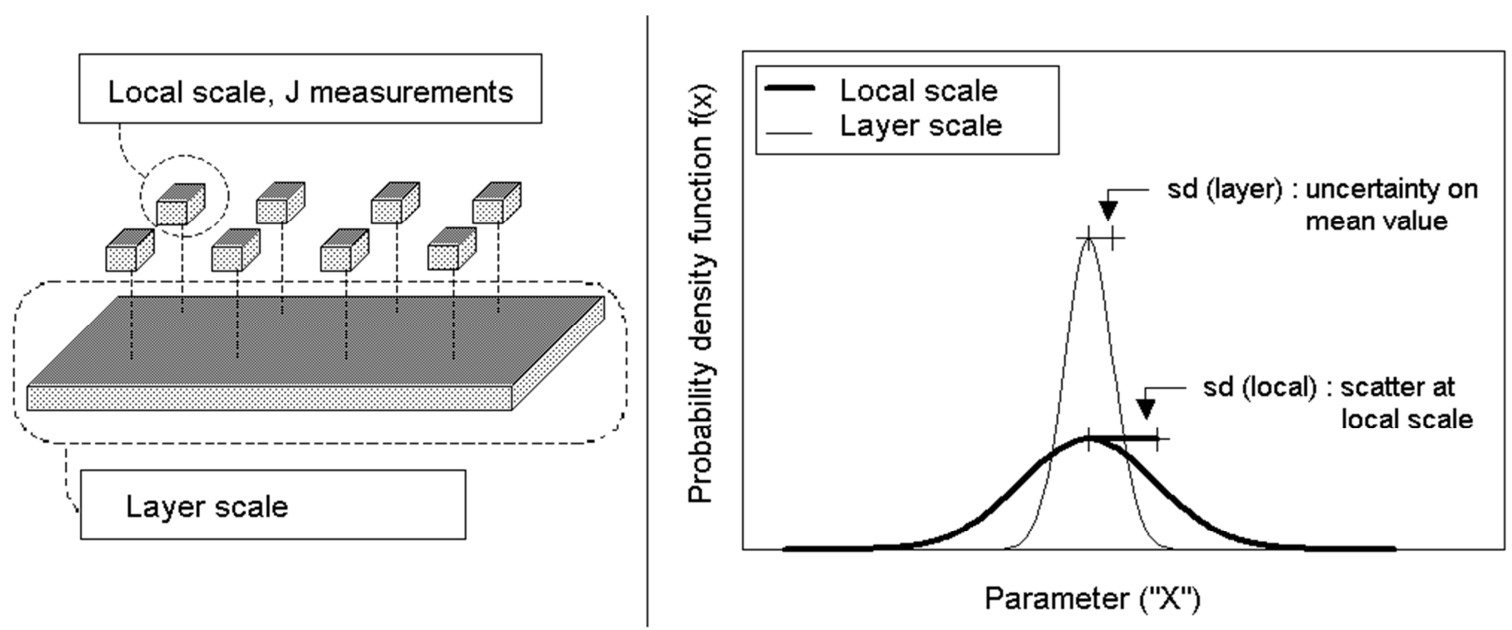

Figure 5. Scatter Diminishes at Larger Scale

At first, this assumption rests on the principle that the mean properties of a volume of RCC layer exhibit less scatter than the local properties obtained from a local test: strong values are compensated for by weak values and larger test volumes benefit from a greater smoothing effect. Moreover, the local measurements performed for the RCC density and compressive strength tests involve similar RCC volumes. Lastly, the two properties are often considered as 
strongly linked. The relationship between RCC density and compressive resistance is not always linear. Nevertheless, for small variations as can be found in RCC, this relation can be linearized. It is therefore legitimate to postulate a conservation of scatter between the two spatial scales (local and RCC layer) for the density and compressive strength parameters.

On the above assumption, the standard deviation of compressive strength at RCC layer scale denoted $\sigma^{\text {Layer }}(f c)_{\mathrm{z}}$ can then be estimated from equation [5] as:

$$
\sigma^{\text {Layer }}\left(f_{c}\right)_{z}=\sigma^{\text {Local }}\left(f_{c}\right) \cdot \frac{\sigma^{\text {Layer }}\left(\gamma_{r c c}\right)_{z}}{\sigma^{\text {Local }}\left(\gamma_{r c c}\right)_{z}}
$$

(iv) We adopt the same type of probability distribution at layer scale as at local scale. If this is a normal distribution, its parameters can be obtained from the mean $\mu(f c)_{\mathrm{z}}$ and standard deviation $\sigma^{\text {Layer }}(f c)_{\mathrm{z}}$.

\subsection{Modelling tensile strengths by unification method}

The tensile strength of RCC mass concrete and RCC construction joints are subject to few or no experimental tests and we cannot have recourse to statistical analysis for this parameter. Traditionally, the engineer faced with this lack of experimental data makes up for the shortage either by taking typical values from engineering handbooks or experts' reports or by deriving them from the compressive strengths by using straight-line empirical functions taken from the technical literature. The more important engineering sources for RCC dams are:

- guidelines and recommendations such as (USACE 2000), (FRCOLD 2006);

- research reports such as (Dolen et al., 1988), (BaCaRa 1996);

- recent dam designs.

In our research, we propose deriving tensile strengths of mass RCC $f_{t \text {-mass }}$ and RCC construction joints $f_{\text {t-joint }}$ from compressive strength $f c$ by using a straight-line function between these parameters $-f_{t \text {-mass }} / f c$ and $f_{t \text {-joint }} / f c$ - as can be found in the technical literature by the data unification method (Shafer, 1976). With this method, we can incorporate all available information on $f_{t \text {-mass }} / f_{c}$ and $f_{t \text {-joint }} / f_{c}$ from the reading list. Installation is a two-step process:

(1) a representation of the information taken from the literature in the form of a probability density: Available information on $f_{t \text {-mass }} / f_{c}$ and $f_{\text {t-joint }} / f c$ ratios may refer to a local value, an envelope of values or a recommended value lying within a range of values. These different information formats can be identified by a probability density shape depending on the information available: uniform, triangular, trapezoidal, etc.;

(2) information unification by weighting each of the sources used: Available information comes from a variety of sources: test results from different mix designs and ages, data from specimens taken from the mixer or cored from the dam. A belief mass can be attributed to this data according to where the specimens were taken from (core drilled from the dam, concrete laboratory, expert opinion), reliability of tracing and relevance to our research. Information unification is then obtained from the sum of probability densities weighted with their belief mass (Figure 6).

In this way, we can estimate a probability distribution for tensile strength (strength of mass RCC or RCC construction joints) by multiplying the probability distributions for compressive strength and $f_{t} / f_{c}$ ratios. 
We thus obtain a probability distribution for tensile strength at local scale or RCC layer scale, depending on whether we use the local scale or RCC layer scale compressive strength probability distribution. The estimated local tensile strength model is then used in the limit state study of crack opening.

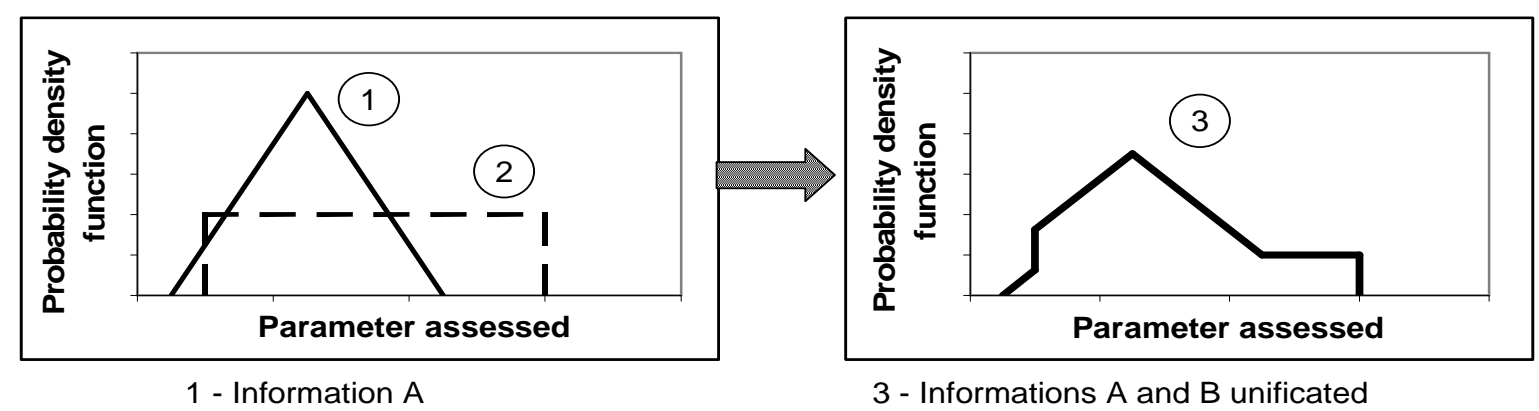

Figure 6. Diagram for Information Unification Method

\subsection{Modelling shear strength through physical relationships}

Some strength parameters can be correlated with each other through physical or empirical factors. If we know the probability distribution for a strength, we can characterise the probability distribution of another parameter by means of the available relationships between these two parameters. This possibility is particularly useful when the parameter being modelled is not amenable to statistical analysis.

There is usually a complete absence of test results that can be used for RCC mass shear strength or construction joint shear strength. We must therefore use the physical relationships between the shear strength parameters $(C$ and $\varphi)$ and the mechanical strength characteristics $\left(f c\right.$ and $\left.f_{t}\right)$ which we had characterised earlier.

The leading models of shear strength - linear, bilinear, parabolic, hyperbolic, etc. - used in dam engineering and found in the technical literature, make use of shear strength parameters (C and $\varphi$ ): (Patton, 1966), (Prat et al., 1991), (Lotfi et al., 1994), (Červenka et al., 1998) and (Puntel et al., 2006).

For our purposes, we take a parabolic model constructed from mechanical strength parameters $\left(f c\right.$ and $f_{t}$ ). The equation for the intrinsic curve is:

$$
\tau=\left[f_{c} \cdot\left(s_{N}+k \cdot f_{c}\right)\left(1+2 \cdot k-2 \cdot \sqrt{k^{2}+k}\right)\right]^{1 / 2} \cdot F
$$

in which:

$-\tau$ is shear strength

$-s_{N}$ is normal stress

$-k$ is the ratio between tensile strength and compressive strength

$-f c, f_{t}$ are compressive and tensile strengths respectively

$-F$ is an adjustment for fitting our model to experimental tests from (Dolen et al., 1988). So the parameter $\mathrm{F}$ is an empirical model used to fit the intrinsic curve better in the range of small normal stresses: 


$$
F=1-\frac{1}{6 \cdot \exp \left(s_{N}\right)}
$$

The formulation [7] represents the equation for the parabola passing through the negative point on the abscissa equal to tensile strength and tangent to the Mohr circle whose diameter is equal to RCC compressive strength.

For the RCC construction joints (Figure 7), we use the parabolic model described above, taking tensile strength on construction joints and compressive strength factored with a reducing coefficient. (Lupien et al., 2004) propose values for factoring compressive strength in consideration of the quality of treatment of the construction joint.

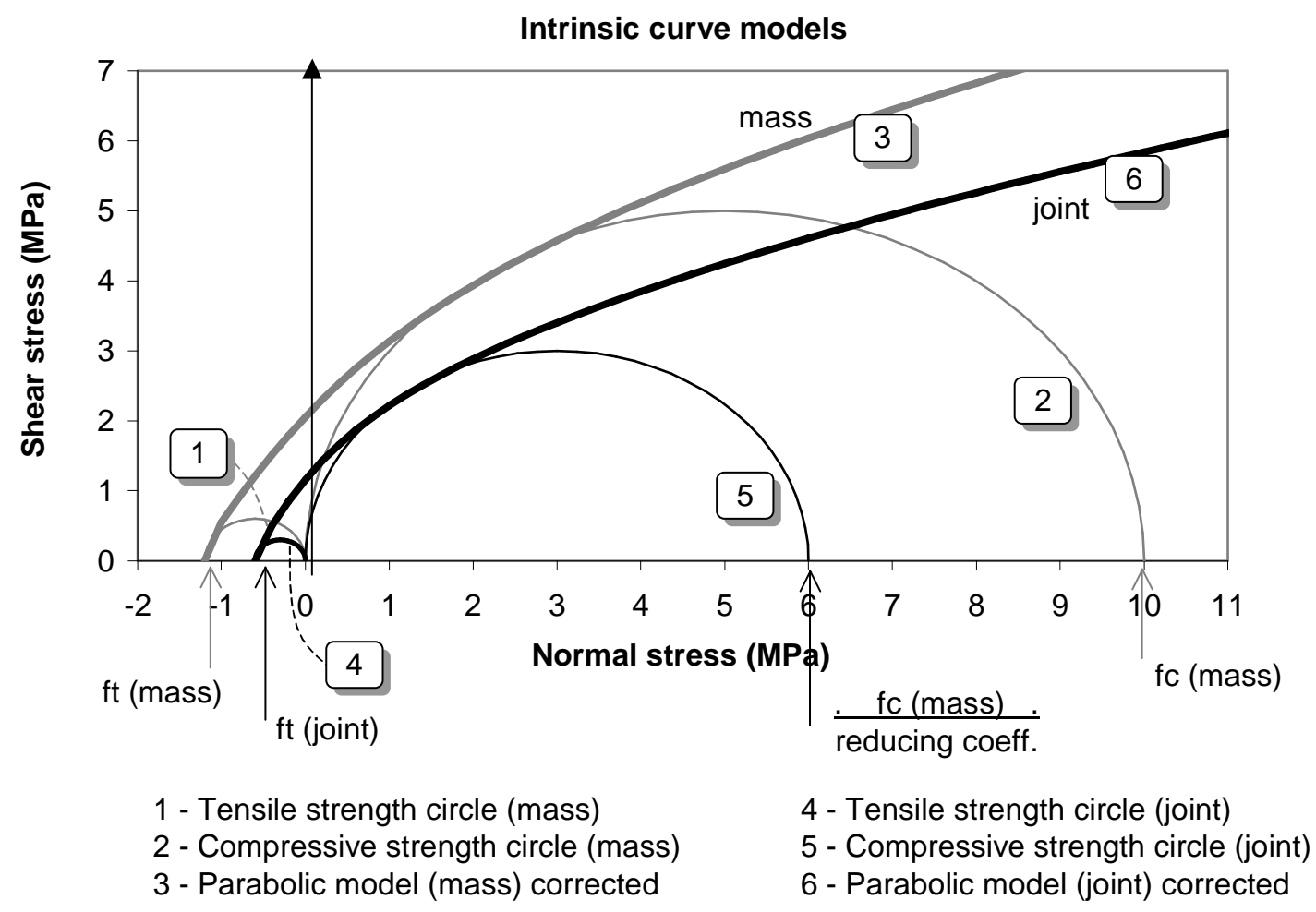

Figure 7. Parabolic Model for RCC Mass and Construction Joint Intrinsic Curve

With the RCC parabolic failure model, cohesion $C$ is found from shear strength for a normal stress of zero. The internal friction angle $(\varphi)$ can be obtained from the secant to the intrinsic curve in the range of realistic normal stresses associated with the water loads acting on the dam (reservoir level and uplift).

With this failure model, we can obtain the variability of the RCC mass and construction joint shear strength parameters at layer scale, as a function of tensile and compressive strength variability. Using Monte Carlo simulations, we generate $\left(f c, f_{t}\right)$ pairs, representing probability distributions at layer scale. These $\left(f c, f_{t}\right)$ pairs determine $(C$ and $\varphi)$ pairs with the intrinsic curve. A statistical adjustment of the sample of $(C$ and $\varphi)$ pairs yields a probability distribution for $(C$ and $\varphi)$ at layer scale. 


\section{Application to RCC gravity dam}

\subsection{Description of case history}

The application examined here concerns an RCC gravity dam in France. Its height above ground level is $46 \mathrm{~m}$, the downstream face has a base/height batter of 0.73 and crest thickness is $4 \mathrm{~m}$. The upstream face is a conventional reinforced concrete wall providing the watertightness to the RCC dam body. Dam body drainage is provided by vertical slots on the rear face of the reinforced concrete wall.

Normal Full Supply Level (RN) is $41 \mathrm{~m}$ (elevation $500 \mathrm{~m}$ asl) and Maximum Water Level (PHE) obtained for the design flood (return period 1000 years) is $42.5 \mathrm{~m}$ (elevation 501.50 asl).

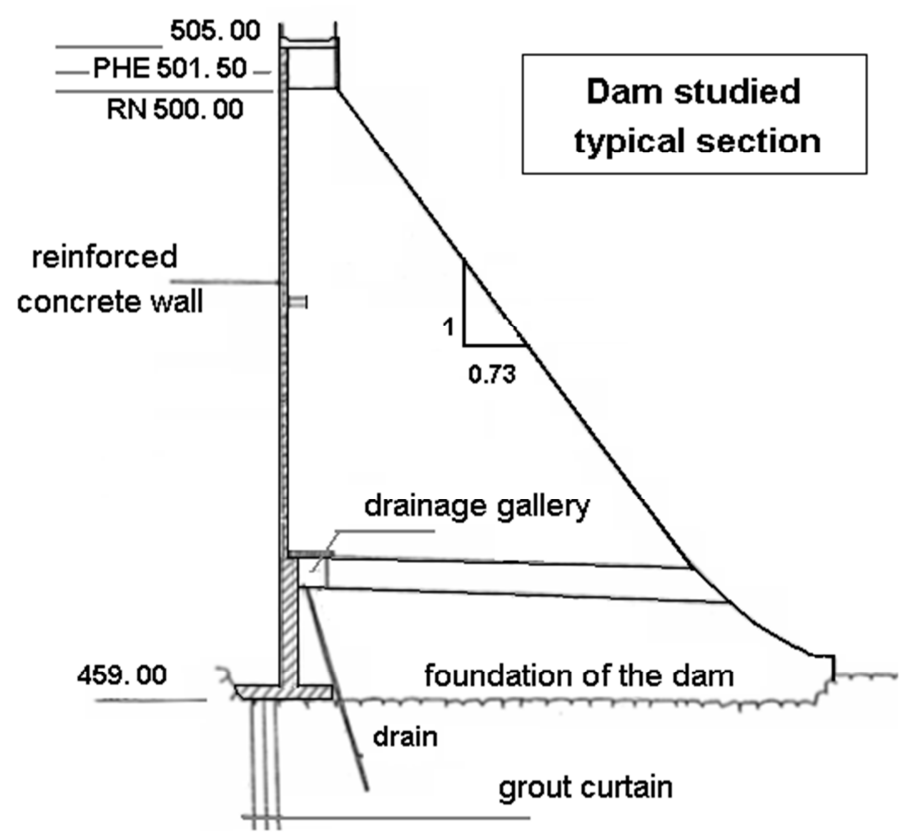

Figure 8. Typical Section through RCC Dam

The RCC mix used in the works contained $120 \mathrm{~kg}$ cementitious material per cubic metre of compacted concrete. It was spread in thin layers, $0.30 \mathrm{~m}$ thick (compacted). The dam therefore has 132 layers of RCC at its highest point. Tests performed on the RCC concrete during the works consisted of (i) density measurements for compaction control (1 test per $200 \mathrm{~m}^{2}$ on average) and (ii) compressive strength tests on two vertical cored boreholes drilled vertically from the crest and drainage gallery on completion of construction (figures 1 and 2 respectively). 


\subsection{Probability modelling of RCC strength parameters}

\subsubsection{Probability modelling of density measured during compaction control}

Statistical analysis of density measurements made to check compaction during construction of the works was conducted at three different scales: local, at RCC construction joints, and the whole dam. The population of density measurements available is a shown in Figure 1:

- at local scale: For each layer, the density is modelled by a probability distribution fitted to available measurement data.

For example, in layer 31, the mean and standard deviation for the ten measurements made are:

$\mu\left(\gamma_{\text {rcc }}\right)_{31}=23.84 \mathrm{kN} / \mathrm{m}^{3}$ and $\sigma^{\text {Local }}\left(\gamma_{\text {rcc }}\right)_{31}=0.19 \mathrm{kN} / \mathrm{m}^{3}$

We can fit a normal distribution agreeing with the previous parameters. A KolmogorovSmirnov conformity test was made to check the relevance of the probability distribution found.

The local scale statistical analysis was done for all the dam layers (figure 9, curves 3 and 4);

- at the scale of an RCC layer: We calculate the mean value for each layer and then estimate the uncertainty attaching to this mean value.

For example, for layer 31, the estimated mean value is represented by a normal distribution with a mean $\mu\left(\gamma_{\mathrm{rcc}}\right)_{31}=23.84 \mathrm{kN} / \mathrm{m}^{3}$ and standard deviation:

$\sigma^{\text {Layer }}\left(\gamma_{\mathrm{rcc}}\right)_{31}=\sigma^{\text {Local }}\left(\gamma_{\mathrm{rcc}}\right)_{31} / 10^{1 / 2}=0.06 \mathrm{kN} / \mathrm{m}^{3}$.

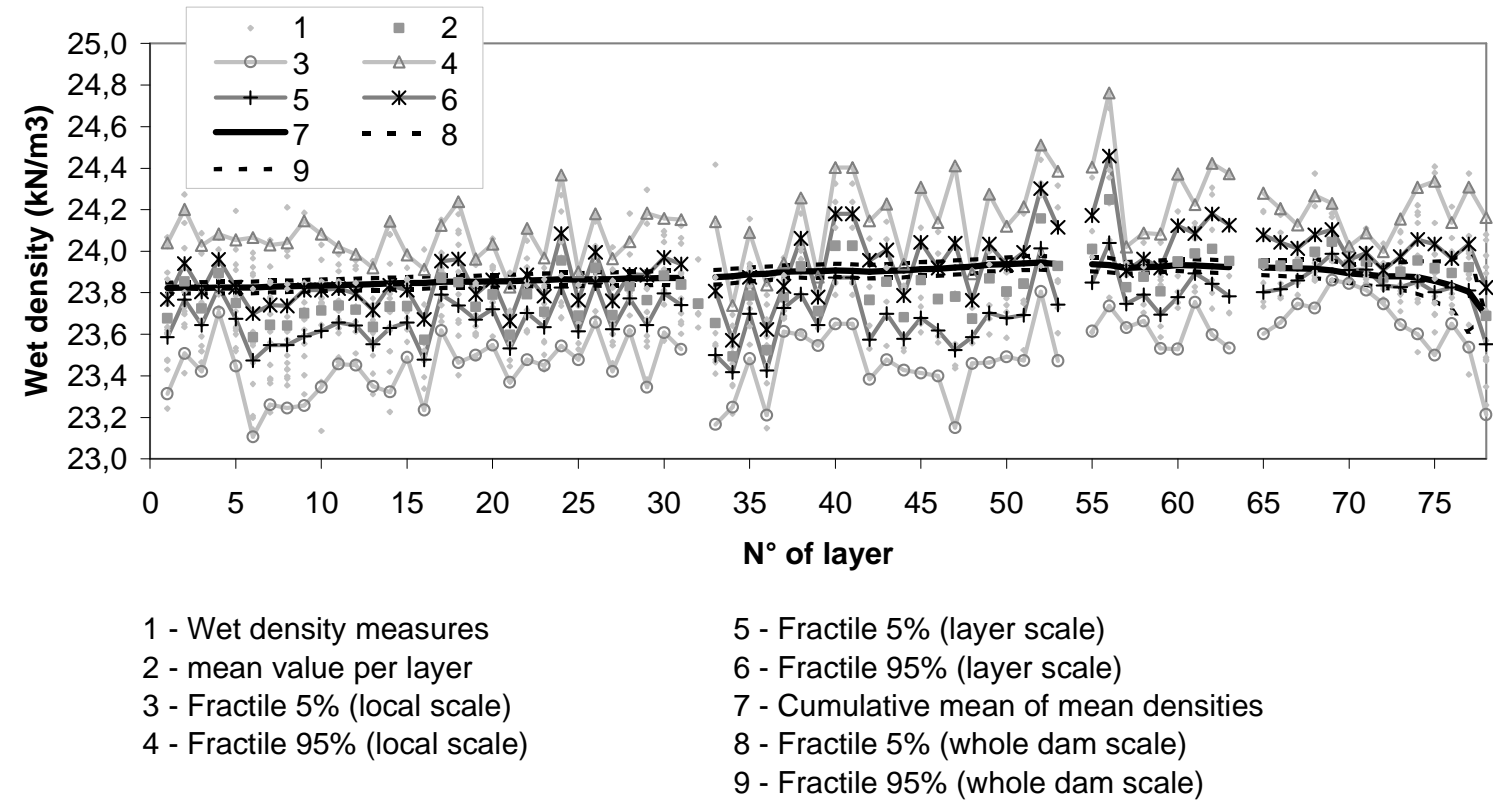

Figure 9. Density Modelling at Local, Layer and Whole Dam Scales

The statistical analysis at layer scale is done for all layers (figure 9, curves 5 and 6).

- at whole dam scale: We calculate the mean of the mean densities of the layers for all layers and estimate the uncertainty attaching to this mean value. 
If we are interested in dam stability as affected by layer 31 , we look for the en value of the mean densities of the layers above layer 31 . We have:

$\mu\left[\mu\left(\gamma_{\text {rcc }}\right)_{31 \mathrm{à} 78}\right]=23.87 \mathrm{kN} / \mathrm{m}^{3}$.

The mean value of the mean densities above layer 31 is represented by a normal distribution with mean $\mu\left[\mu\left(\gamma_{\mathrm{rcc}}\right)_{31 \mathrm{à} 78}\right]=23.87 \mathrm{kN} / \mathrm{m}^{3}$ and standard deviation:

$\sigma^{\text {Dam }}\left(\gamma_{\mathrm{rcc}}\right)_{31}=\sigma\left[\mu\left(\gamma_{\mathrm{rcc}}\right)_{31 \mathrm{à} 78}\right] /(48)^{1 / 2}=0,02 \mathrm{kN} / \mathrm{m}^{3}$

The Kolmogorov-Smirnov test was performed to check the relevance of the probability distribution found.

The statistical analysis at whole dam scale can be done for all the layers together (figure 9, curves 7,8 and 9 ).

To sum up, the fractiles for the different spatial scales involving layer 31 reveal the relative scatter between scales (Figure 10). This logically demonstrates that uncertainty diminishes as the scale of analysis increases.

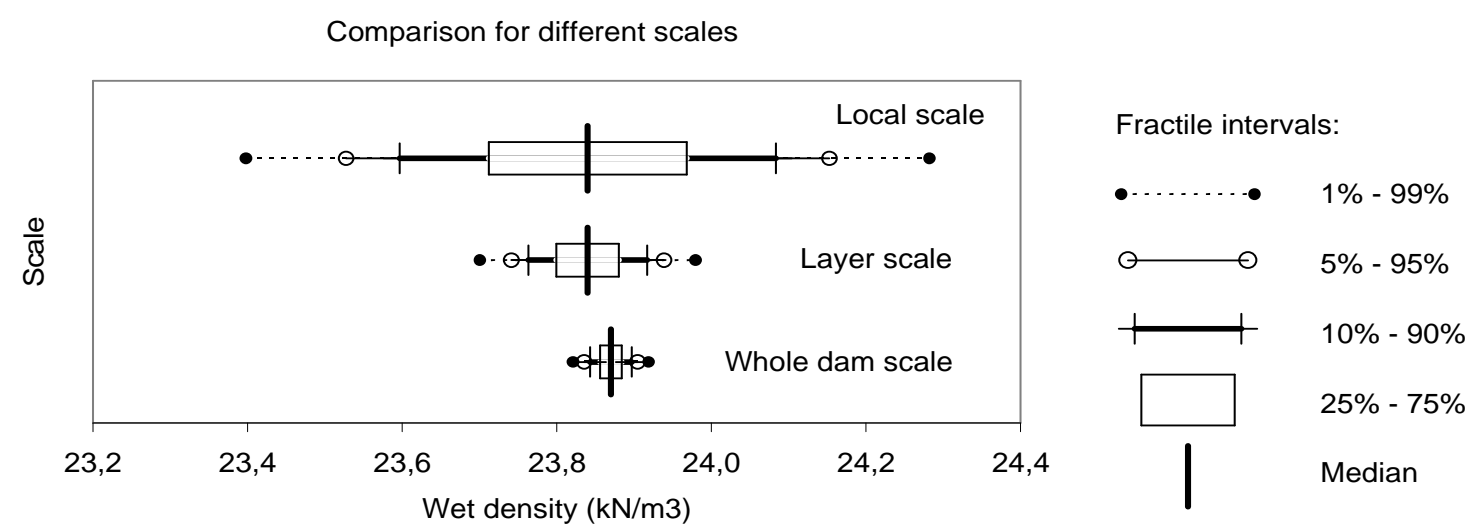

Figure 10. Scatter in Densities vs Spatial Scale - Example for RCC layer 31

\subsubsection{Modelling compressive strength}

For the dam in question, we have a population of 28 values for compressive strength $f_{c}$ from tests on drill core (Figure 2). We perform a statistical analysis of these values and then fit a normal distribution corresponding to the variability of the parameter at local scale (Figure 11). This determines the scatter in the compressive strength values at local scale: $\sigma^{\text {Local }}(f c)=3.2$ MPa. 


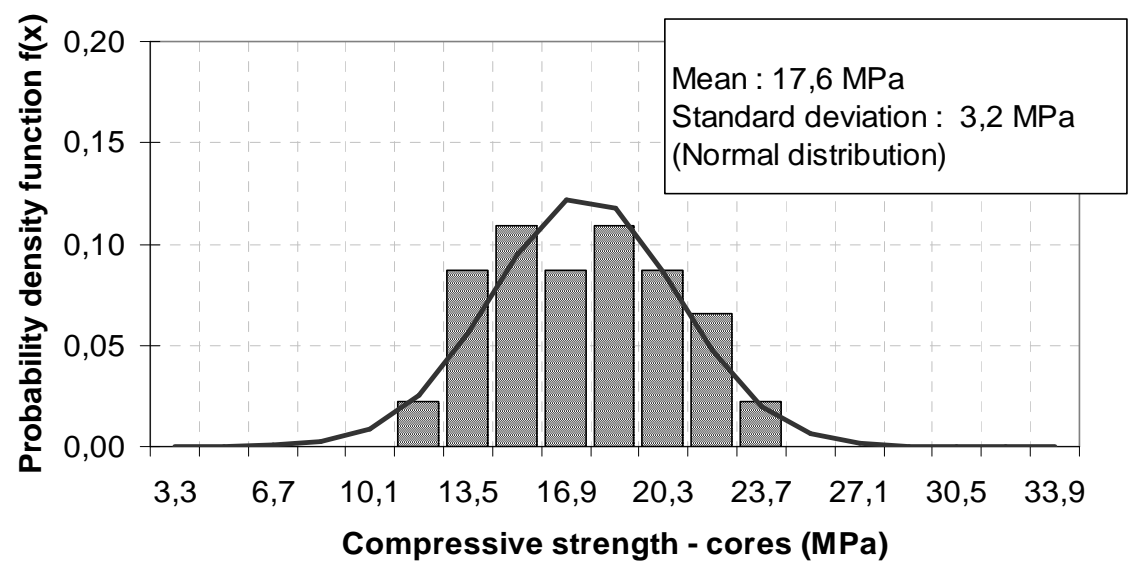

Figure 11. Fitting a Normal Distribution for $f c$

At dam layer scale, compressive strength scatter is obtained by means of the assumption of conservation of scatter ratios between density and compressive strength. For each layer $\mathrm{z}$, the standard deviation at layer scale for compressive strength $\sigma^{\text {Layer }}(f c)_{\mathrm{z}}$ is found with the Equation [6].

We use the same type of probability distribution at layer scale as at local scale. For each layer, the mean of the normal distribution corresponding to he scale of the layer is obtained by smoothing the compressive strength curve (curve 1, Figure 12).

Compressive strength variability study at local and layer scales at each layer is synthesized in the next figure:

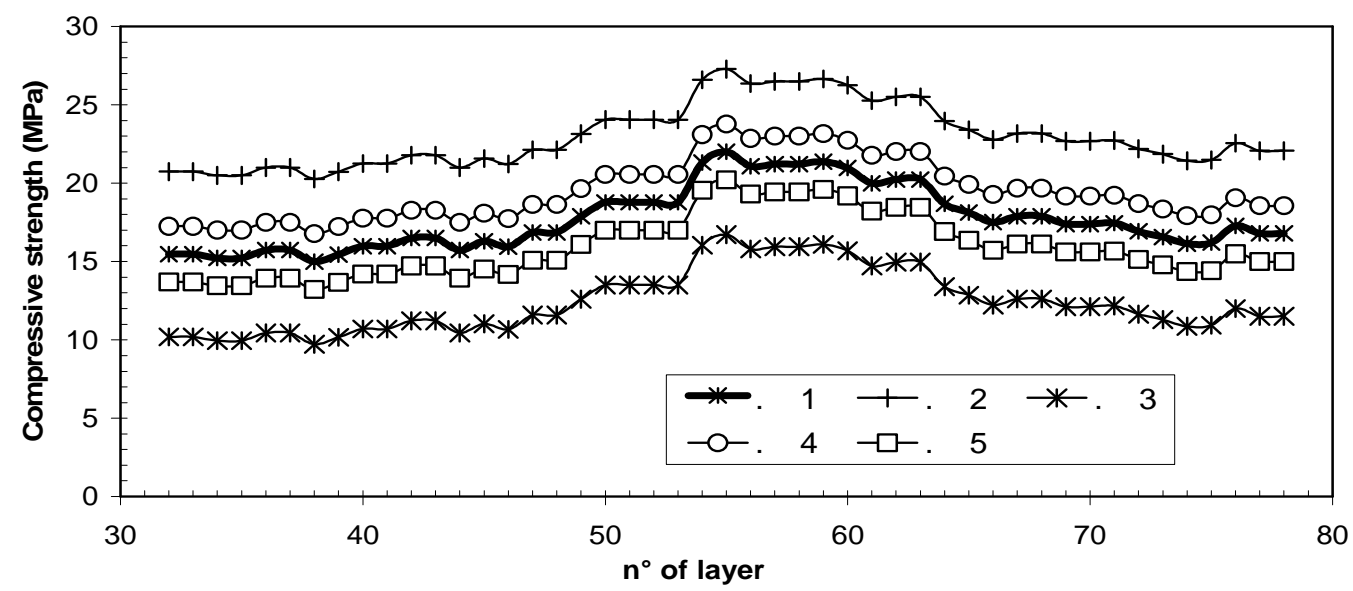

1 - fc (smoothed)

2 - Fractile $95 \%$ (local scale)

3 - Fractile 5\% (local scale)

4 - Fractile 95\% (layer scale)

5 - Fractile 5\% (layer scale)

Figure 12. Compressive Strength Variability at Local and Layer Scales 


\subsubsection{Tensile strength}

\subsubsection{Determination of $f_{t} / f_{c}$ Ratio}

No tensile strength tests were performed on the dam. To estimate tensile strength variability, we propose using the reference titles dealing with the $f_{t} / f_{c}$ ratio through a data unification procedure. Each data element is represented by a probability density an is assigned a belief mass as dictated by the quality of the information and its relevance to the problem in hand.

The outcome of the information unification process is a probabilistic representation of the $f_{t} / f c$ ratio. Then a probability distribution is fitted to this probabilistic representation. These manipulations are performed on data relevant to ratios in the mass of the RCC (ratio $f_{t \_m a s s} / f_{c}$ ) and at the construction joints (ratio $f_{t_{-} \text {joint }} / f c$ ). Figure 13 illustrates the data unification exercise on construction joint data.

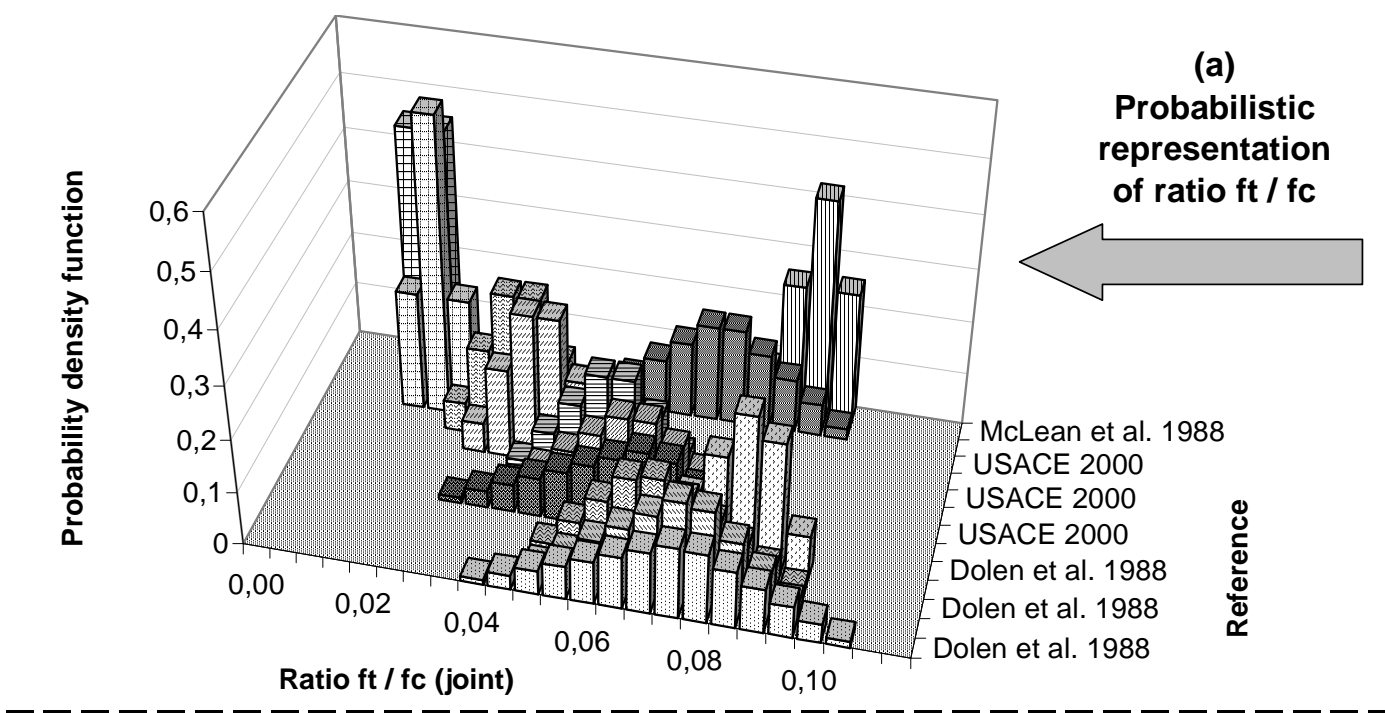

(b)

ratio ft / fc data unificated
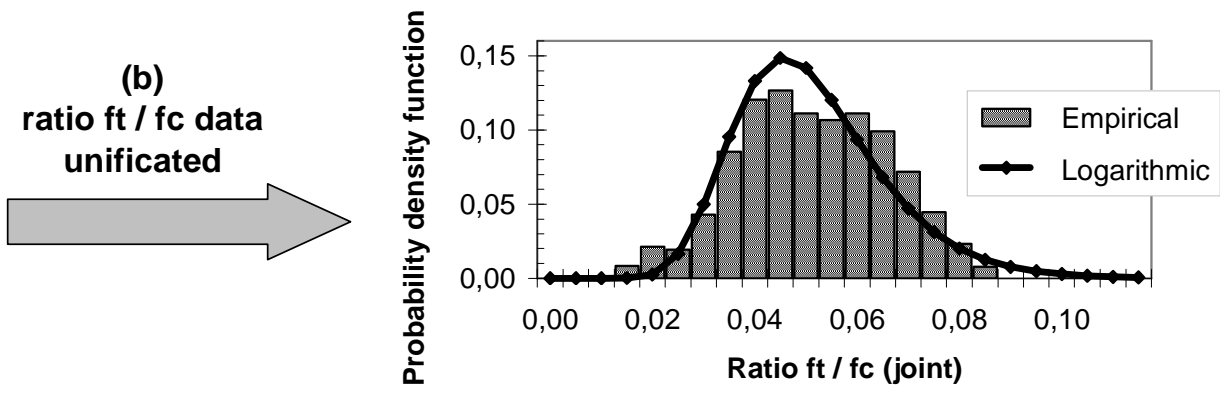

Figure 13. Probability Modellling of $f_{t \_j o i n t} / f c$ Ratio

\subsubsection{Determination of tensile strength}

The tensile strength probability distribution in the RCC mass and at construction joints is obtained by multiplying the probability distribution of ratio $f_{t} / f_{c}$ by the probability distribution of $f c$.

Depending on whether we take, for $f c$, the probability distribution at local scale or RCC layer scale, the multiplication yields the tensile strength $f_{t}$ with the local or layer-scale probability distribution. The probability distribution $f_{t}$ at local scale is used for assessing crack opening; 
local scale results are used for crack width details, layer scale results indicate the variability of shear strength parameters.

Multiplication of probability distributions is done with Monte Carlo simulations. Computational results for tensile strength on construction joints are presented on Figure 14 at local and layer scales.

Tensile strength obtained by data unification process and simulations

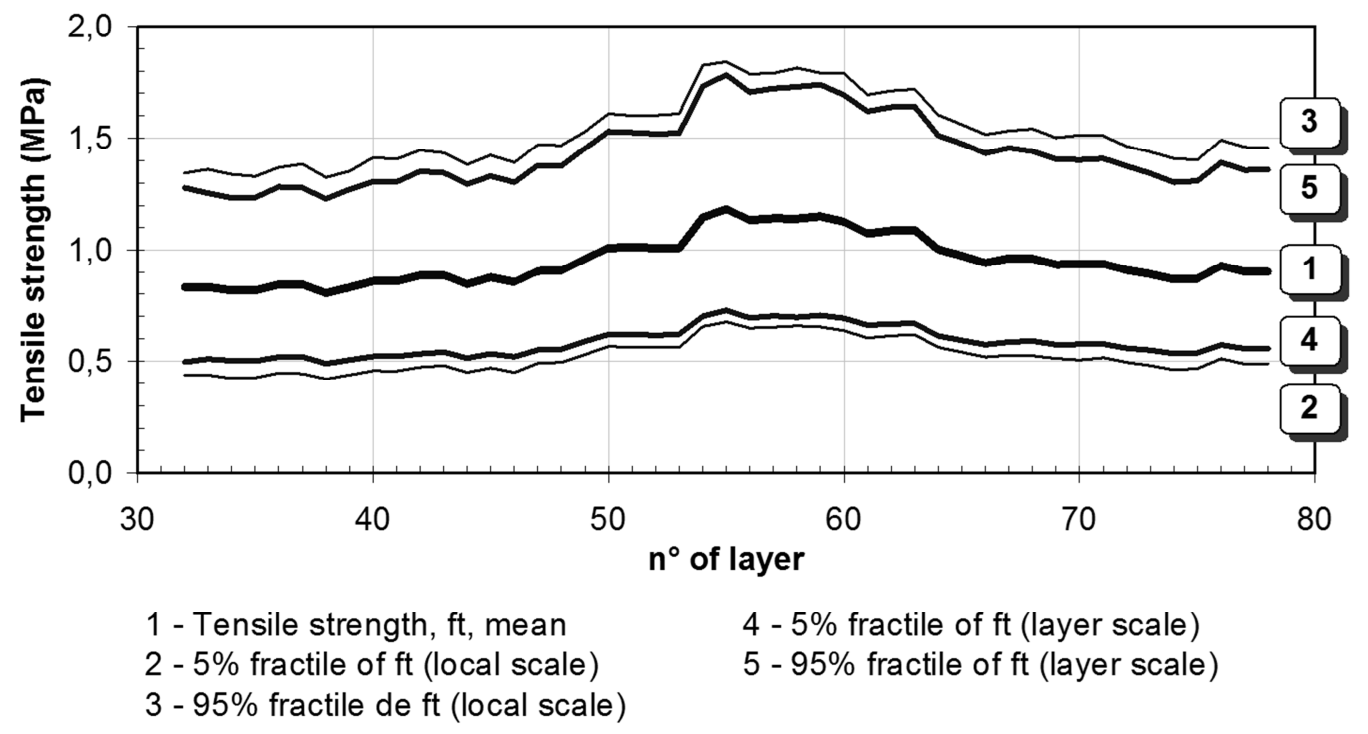

Figure 14. Variability of Tensile Strength $f_{t-j o i n t}$ at local scale and layer scale

\subsubsection{Shear strength}

There were no shear tests performed on the dam in question. The variability of shear strength parameters was estimated from probability distributions at layer scale for tensile and compressive strengths and with the formulation chosen for the RCC intrinsic curve. Monte Carlo simulations were then run: for each $\left(f c, f_{t}\right)$ pair generated by random selection using probability distributions for $f t$ and $f c$, we determine, through the intrinsic curve equation, a pair $(C$ and $\varphi)$. The statistical study of the sample of $(C$ and $\varphi)$ pairs thus generated allows us to associate a probability distribution for the two parameters $C$ and $\varphi$.

Figure 15 shows the probability modelling of shear strength for a given layer of the dam. It represents the mean intrinsic curve for this layer, which we obtained with the means of probability distributions for $f_{t}$ and $f c$ at this layer scale. It also shows the intrinsic curves for the $5 \%$ and $95 \%$ fractiles for $f_{t}$ and $f c$. 


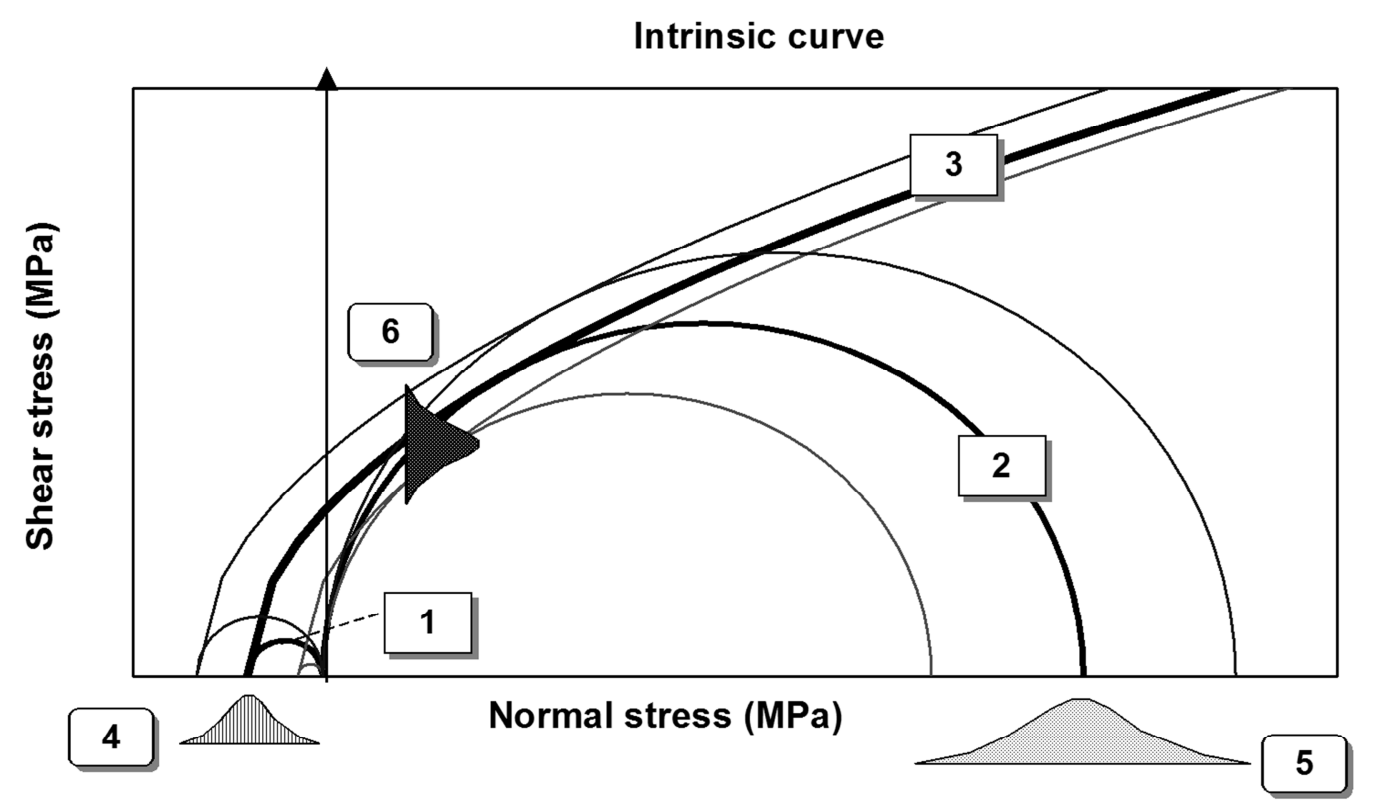

1 - Tensile circle (mean, $5 \%$ fractile and $95 \%$ fractile)

2 - Compressive circle (mean, $5 \%$ fractile and $95 \%$ fractile)

3 - Intrinsic curve

4 - Tensile strength probability density diagram

5 - Compressive strength probability density diagram

6 - Shear strength probability density diagram

Figure 15. Variability of Intrinsic Curve versus Variability of Tensile and Compressive Strengths for a Given Layer of the RCC dam

This analysis gives the variability of the shear strength parameters at layer scale. Figure 16 and 17 show the results obtained for the dam under study for the cohesion and internal friction angle in a normal stress range which would occur in the dam under operational conditions.

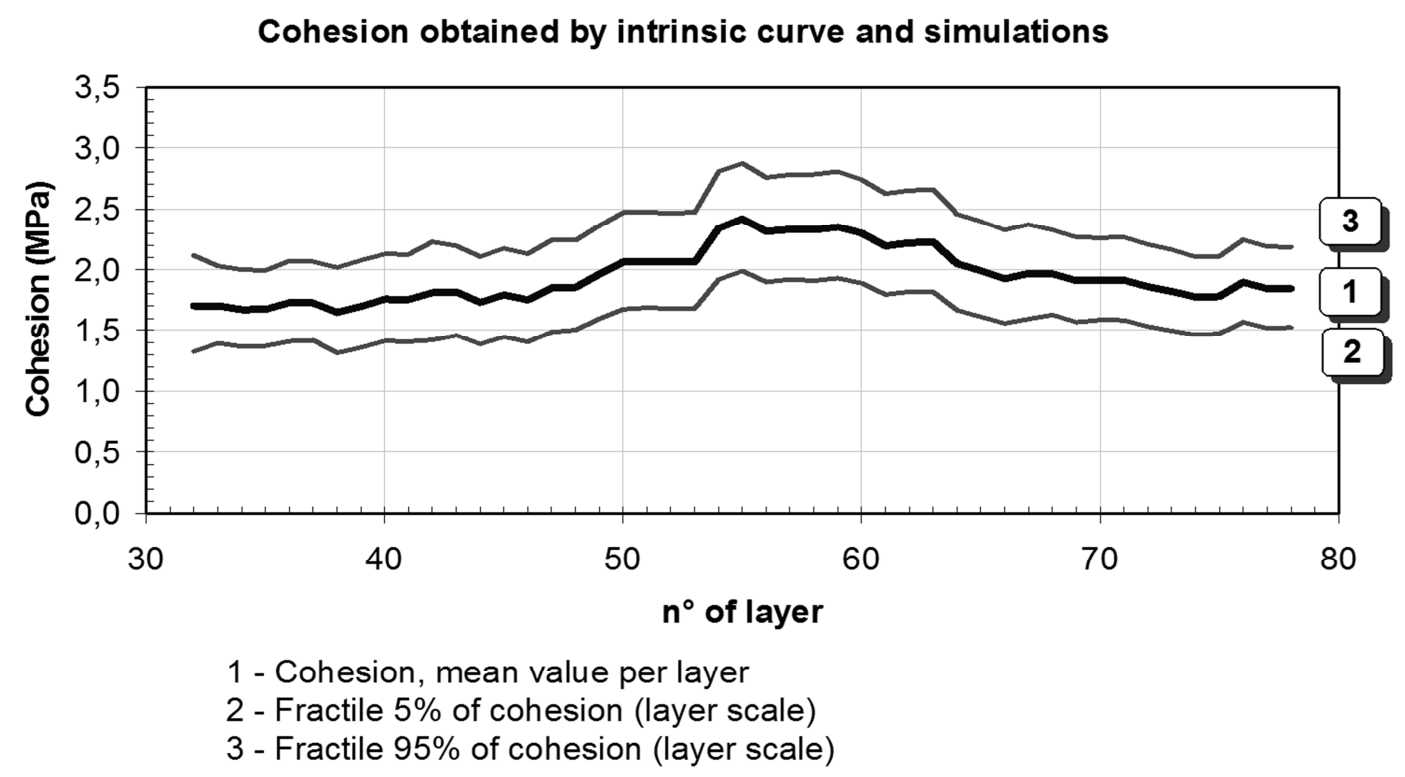

Figure 16. Variability of Cohesion at Layer Scale of the Dam under study. 
Tan(Phi) obtained by intrinsic curve and simulations

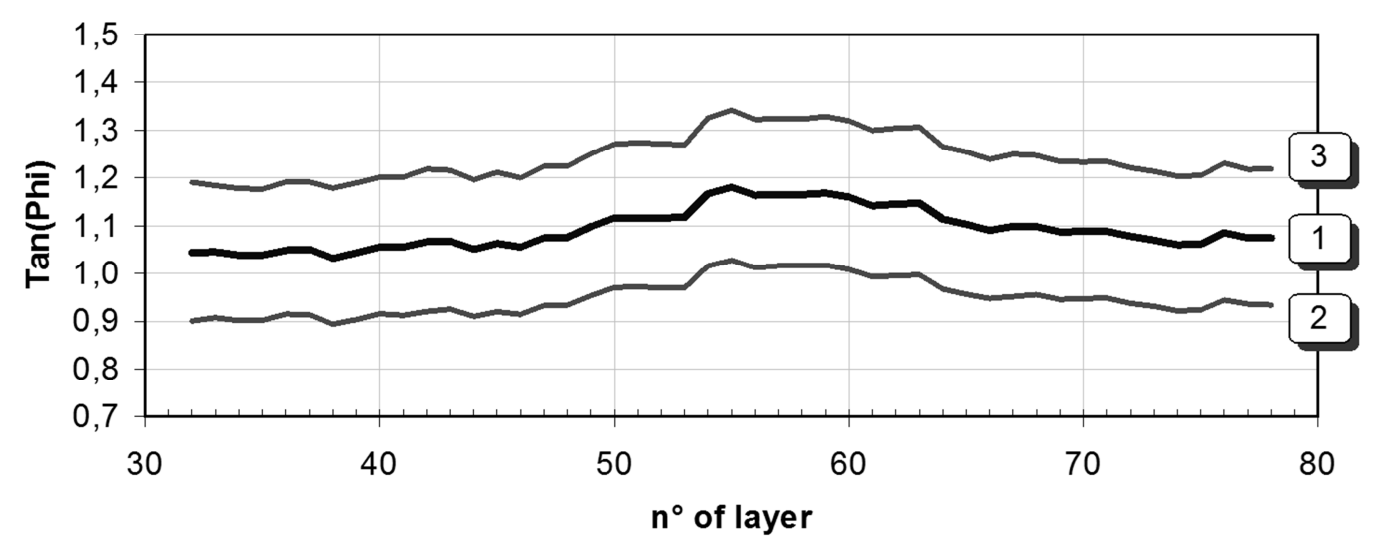

1 - Tangent of internal friction angle, $\tan (\mathrm{phi})$, mean value

2 - Fractile $5 \%$ of Tan(phi) (layer scale)

3 - Fractile $95 \%$ of Tan(phi) (layer scale)

Figure 17. Variability of tan $(\varphi)$ at Layer Scale of the Dam under study.

\subsection{Assessment of structural safety}

\subsubsection{Performance functions associated with limit states}

In a reliability study, the limit states are included by means of performance functions. With gravity dams, we are concerned with the shear strength limit state. Shear strength is represented by the performance function $G_{l}$ :

$$
G_{1}: C \cdot L^{\prime}+(N-U) \cdot \tan (\varphi)-T
$$

in which:

$-C$ and $\varphi$ are the cohesion and internal friction angle parameters of the dam materials

$-N$ and $T$ are the normal and tangential components respectively of the external forces acting on the top part of the section under study

$-U$ is the resultant of pore pressures at the section under study

$-L^{\prime}$ is the crack-free length of the horizontal section under study. The crack-free length of the horizontal section is determined by an iterative process based on the no-crack condition (equation [1])

If $G_{1} \leq 0$, we are in the fault zone and the section of the dam under study fails in shear. If $G_{l}>$ 0 , we are in the safe zone and the dam remains damage-free.

\subsubsection{Definition of random variables (strengths and loads)}

The random variables representing the properties of the RCC at different spatial scales have been assessed by the procedures described in this paper. Table 1 lists the probability distributions of strength parameters obtained at the level of the lowest RCC layer in the dam in a typical application of the method. 
The principal load acting on dams is the water load. For our application, water load is set in terms of the normal reservoir level (RN) 41 metres above foundation line and maximum reservoir level (PHE) at $42.5 \mathrm{~m}$ above foundation line.

Table 1. Probability distributions for RCC parameters for dam studied at different scales

\begin{tabular}{|c|c|c|c|}
\hline Random Variable & $\begin{array}{c}\text { Probability } \\
\text { Distribution }\end{array}$ & Mean & Standard Deviation \\
\hline $\begin{array}{c}\text { Unit weight, } \gamma_{\mathrm{rcc}} \\
\text { (at whole dam scale) }\end{array}$ & Normal & $23.2 \mathrm{kN} / \mathrm{m}^{3}$ & $0.016 \mathrm{kN} / \mathrm{m}^{3}$ \\
\hline $\begin{array}{c}\text { Compressive strength, } f c \\
\text { (at layer scale) }\end{array}$ & Normal & $15.5 \mathrm{MPa}$ & $1.6 \mathrm{MPa}$ \\
\hline $\begin{array}{c}\text { Tensile strength, } f_{t} \\
\text { (at local scale) }\end{array}$ & Log-Normal & $0.83 \mathrm{MPa}$ & $0.8 \mathrm{MPa}$ \\
\hline $\begin{array}{c}\text { Cohesion, } C \\
\text { (at layer scale) }\end{array}$ & $\begin{array}{c}\text { Normal, truncated } \\
\text { at } 0\end{array}$ & $1.7 \mathrm{MPa}$ & $0.23 \mathrm{MPa}$ \\
\hline $\begin{array}{c}\text { Friction tan }(\varphi) \\
\text { (at layer scale) }\end{array}$ & Normal & 1.05 & 0.08 \\
\hline
\end{tabular}

In modelling water load, we can account for the random nature of the water level by taking a Gumbel distribution since this type of distribution is routinely used to represent the hydrological variables governing reservoir level, (FRCOLD 1994).

In our application, we determine the parameters of the Gumbel distribution modelling reservoir level by considering that the maximum reservoir level (PHE) is associated with a probability of $10^{-3}$ and that the normal reservoir level (RN) sets the mean reservoir level (Table 2).

Uplift pressure acting the dam body is directly proportional to the upstream water load (FRCOLD 2006). In computing uplift pressure loads, allowance is made for the lowering of uplift pressure due to the drainage system, which leads to a reduction in the uplift pressure diagram. The efficiency of the drainage is accounted for with a reduction coefficient. Guidance on the value of this reduction coefficient suggests 0 to 2/3 (FRCOLD 2006). In this application, uncertainty on drainage system efficiency is allowed for by a normal distribution representing the uplift pressure reduction (Table 2).

Table 2. Probability distributions used to model loads acting on dam

\begin{tabular}{|c|c|c|}
\hline Random variable & Probability distribution & Parameters \\
\hline Flood water level & Gumbel & $\mu: 41 \mathrm{~m}$ \\
$\sigma: 1.22 \mathrm{~m}$
\end{tabular}

The correlation matrix of random variable values appears in Table 3 below. 
Table 3. Correlation of random variables in the study

\begin{tabular}{|c|c|c|c|c|c|c|}
\hline Correlations & $\begin{array}{c}\text { Unit } \\
\text { weight }\end{array}$ & $\begin{array}{c}\text { Tensile } \\
\text { strength }\end{array}$ & Cohesion & $\operatorname{Tan}(\varphi)$ & $\begin{array}{c}\text { Flood } \\
\text { water } \\
\text { level }\end{array}$ & Drainage \\
\hline Unit weight & 1 & 0.2 & 0.3 & 0.2 & 0 & 0 \\
\hline Tensile strength & 0,2 & 1 & 0,6 & -0.1 & 0 & 0 \\
\hline Cohesion & 0.3 & 0.6 & 1 & -0.2 & 0 & 0 \\
\hline Tan $(\varphi)$ & 0.2 & -0.1 & -0.2 & 1 & 0 & 0 \\
\hline Flood water level & 0 & 0 & 0 & 0 & 1 & 0.2 \\
\hline Drainage & 0 & 0 & 0 & 0 & 0.2 & 1 \\
\hline
\end{tabular}

\subsubsection{Assessment of structural safety}

The failure probability, $P f$, for the shear strength limit state in the lowest RCC dam layer, assessed with the FORM method and Monte Carlo simulations is presented in Table 4.

Table 4. Assessment of structural safety by FORM method and Monte Carlo simulations

\begin{tabular}{|l|l|l|l|}
\hline Limit state & $P f($ Monte Carlo) & $P f($ FORM $)$ & $\beta$ (FORM) \\
\hline Shear strength & $<1.0 \times 10^{-7}$ & $<1.0 \times 10^{-7}$ & 6.45 \\
\hline
\end{tabular}

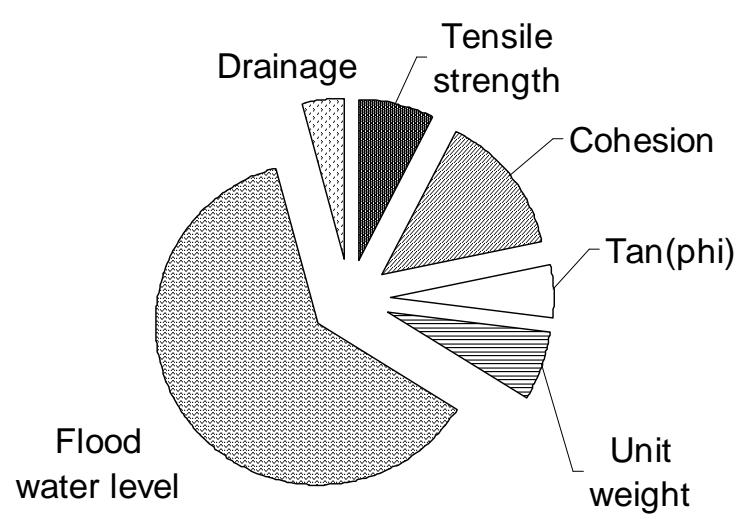

Figure 18. Sensitivities of Shear Probabilities to Random Variables

The results obtained by the FORM method and Monte Carlo simulations indicate a very slight probability of failure of the dam with respect to the shear strength limit state. The value obtained for coefficient $\beta$ is much higher than the recommended minimum values specified in Eurocode 0 for other civil engineering works, a fact which reveals that dam design demands very high standards of safety with respect to the limit state analysed. 
The sensitivity of the random variables on the question of structural safety can be assessed with the FORM method. We look for the direction cosines of the most probable failure point in a standard probability space (with standardised variables) are shown in Figure 18 below for shear strength limit states.

From this figure, we can identify the random variables having the strongest influence on failure probability. The key points are:

(1) among load variables - upstream water load represented by reservoir level, uplift pressure represented by drainage, dead weight represented by unit weight of materials, it is logically the upstream water load that is the most important item in terms of structural safety. This is another example of the importance of the maximum water level in dam engineering;

(2) Among the strength variables, it is the cohesion and, to a lesser extent, the tensile strength which are preponderant. We also have before us another familiar finding in conventional deterministic dam engineering, which is that the characteristic values assigned to $C$ and $f_{t}$ are key contributors to the overall dam safety factor.

\section{Conclusion}

Our research was aimed at finding a method of probability modelling strength parameters which would make use of all available information, in particular, the records of the tests performed during construction of the dam. The ultimate objective was to find a way past the obstacles to reliability modelling of dam concrete, viz. (i) the small number of shear tests performed on the constructional materials and (ii) available tests not being directly relevant to the strength parameter involved in limit state practice.

In addition to this, the variability of RCC properties and the estimation of uncertainties must be studied with allowance for the size of the zone concerned by the limit states being considered: (1) cracking concerns the upstream portion of an RCC layer and cracking conditions are potentially different from one layer to another. Therefore the probability distribution for tensile strength must be looked for at local scale along the upstream dam face of the dam; (2) a deficiency in shear strength calls upon the mean shear strength of an RCC layer. Consequently, the probability distribution for shear strength must be studied on an RCC layer or construction joint. Proposed methods must therefore be modified to suit the different spatial scales of uncertainty attaching to the properties of these materials.

Considering these obstacles, our research made use of all available information, in particular data on the tests performed during construction. We put forward an approach making use of various methods eventually leading up to a probabilistic modelling of RCC shear strength:

(1) statistical analysis of measured densities from the compaction control tests: we propose analysing the variability of density measurements, of which there was a plentiful supply from the time of the RCC compaction control tests, to assess scatter at the different spatial scales at local scale, at RCC layer scale, and at the scale of the whole dam;

(2) modelling of compressive strength by analysis of density scatter: available instrumental data from compressive strength tests (on drill core and specimens taken from the mixing plant) can be used for statistical analysis at local scale only. Since we do not have sufficiently abundant compressive strength records for individual RCC layers, we suggest using the ratios between local- and layer-scale density scatter from the compaction control tests. We are thus 
arguing for a probabilistic modelling of the RCC compressive strength at layer scale. In this way, we propose a probabilistic modelling of compressive strength at RCC layer scale;

(3) modelling of tensile strength by the unification method. Taking the model obtained in (ii) for compressive strength, we use a data unification technique to model tensile strength at layer and local scales. The data unification technique makes use of the various available engineering sources for correlations between tensile and compressive strength such as engineering handbooks and similar publications, experts' reports and research projects;

(4) modelling of shear strength by a physical relationship: taking a physical expression of the RCC intrinsic curve using mechanical strength parameters only, we can assess the shear strength parameters at layer scale. This has the further advantage that modelling the shear strength parameters also involves the value of the normal stress acting on the dam, which exerts a discernible influence on the assessment of the parameters.

The case history reveals the applicability of this method to an existing RCC dam, using instrumental data from the construction records and engineering tests performed in the course of construction. In modelling the RCC properties in this way, we can proceed on to a probabilistic reliability assessment of the structural safety of the dam. The modelled strengths are introduced into the formulation of the shear strength limit state by means of a First Order Reliability Method - FORM - and Monte Carlo simulations. The FORM analysis yields the sensitivity of the failure probability under different random variables, enabling us to find the sensitivities of cohesion and tensile strength parameters in the design computations, where designers are on familiar ground.

This research is part of a much wider R\&D project to develop probabilistic reliability methods for assessing the structural safety of dams. Otherwise, the probabilistic models discussed in this article could found applications with Finite Element Method (FEM) numerical analyses. Earlier developments in the modelling of hydrostatic loads have been put forward (Carvajal et al., 2008). Current work focuses on the probabilistic modelling of other types of material: dam-foundation interface and the foundation rock itself. In addition, an experimental research programme on operational gravity dams is hoped to characterise mass concrete materials. There will be non-destructive instrumental data collection backed up by large diameter drilling for video and IR inspection.

\section{References}

BaCaRa, Le béton compacté au rouleau, les barrages en BCR, Projet National BaCaRa 1988-1995. Paris: Presses de l'ENPC, 1996.

Carvajal C., Peyras L., Arnaud P., Boissier D., Royet P., "Probabilistic modelling of flood water level for dams reservoirs". Accepted In Journal on Hydrologic Engineering, 2008.

Carvajal C., Peyras L., Bécue J.P., Varon C, Bacconnet C., Clergue D., Boissier D., "Towards a Probabilistic Assessment of Structural Safety of Gravity Dams". In: 7th ICOLD European Club and 14th German Dam Symposium. Freising, Germany, 17-19 September 2007, pp. 64-69.

Červenka J., Chandra J-M. et Saouma V., "Mixed Mode Fracture of Cementitious Bimaterial Interfaces Part II". Eng. Fracture Mechanics Vol.60, No.1, pp95-107, 1998.

Dolen T, Richardson A, White W., "Quality Control/Inspection - Upper Stillwater dam". In Roller Compacted Concrete II. New York: ASCE, 1988. pp. 277-293.

Ellingwood B.R., Tekie P.B., 2001. "Fragility Analysis of Concrete Gravity Dams". In: Journal of Infrastructure Systems, Vol. 7, No. 2, June 2001, pp. 41-48. 
Favre J-L. Sécurité des ouvrages. Risques. Modélisation de l'incertain, fiabilité, analyse des risques. Editions Ellipses, 2004.

FRCOLD, 2006. Recommandations pour la justification pour la stabilité des barrages - poids. Propositions de recommandations. FRCOLD, 2006.

FRCOLD, 2002. Small dams - Guidelines for Design, Construction and Monitoring, Cemagref Editions, Paris, 2002.

FRCOLD, 1994. Design flood Determination by the Gradex method. French Committee on Large Dams publications., November 1994.

Lotfi H., Shing B., "Interface Model Applied to Fracture of Masonry Structures". In: Journal of Structural Engineering. ASCE, 1994. Vol.120 No. 1., 1994, pp 63-80.

Lupien R., Tremblay S., Lizotte M., Robitaille F. et Prezeau A., "Innovations in Roller Compacted Concrete Testing". Canadian Dam Association Annual Conference, Ottawa, Ontario, Canada, September 2004.

McDonald L.A., Wan C.F., Risk Assessment for Hume Dame- Lessons from estimating the chance of failure. ANCOLD Bulletin No. 112, 1999.

McLean F., Pierce J., "Comparison of joint shear strengths for conventional and roller compacted concrete". In: Roller Compacted Concrete II. ASCE, 1988. pp. 151-169.

Patton, F.D., 1966. "Multiple Modes of Shear Failure in Rock and Related Materials". PhD thesis, University of Illinois, 1966.

Peyras L., Royet P., Deroo L., Albert R., Becue J-P., Aigouy S., Bourdarot E., Loudiere D., Kovarik JB., "French Recommendations for Limit-State Analytical Review of Gravity Dam Stability", European Journal of Environmental and Civil Engineering, Vol. 12, n 9, 2008, p.1137-1164.

Prat P.C., Carol I., Gettu R., "Numerical Analysis of mixed-mode fracture of quasi-brittle materials using a multicrack constitutive model". Proc., Int. Conf. On Mixed-Mode Fracture and Fatigue, Chapman and Hall, Austria, 1991.

Puntel E., Bolzon G. et Saouma V., "A fracture mechanics based model for joints under cyclic loading”. In-print ASCE Journal of Engineering Mechanics, 2006.

Shafer G., "A mathematical Theory of evidence”, Princeton University Press, 1976.

USACE, Gravity Dam Design. Washington: US Army Corps of Engineers Report EM 1110-2-2200, June 1995.

USACE, "Reliability and Stability Assessment of Concrete Gravity Structures (RCSLIDE)". US Army Corps of Engineers, 1998, Technical Report ITL-98-6.

USACE, Rolled-Compacted Concrete. Washington: US Army Corps of Engineers, January 2000, Report EM 1110-2-2006.

USBR, Design of Small Dams. US Bureau of Reclamation (3 ${ }^{\text {th }}$ Ed. $), 1987$. 